\title{
Evaluation of cortical arousal by critical flicker fusion threshold in cyclists
}

\author{
Vicente Javier Clemente-Suarez \\ Universidad Europea de Madrid \\ Faculty of Sport Science \\ Grupo de Investigación en Cultura, Educación y \\ Sociedad. Universidad de la Costa. Barranquilla. \\ Colombia Department of Sport Sciences. Calle \\ Tajo, s/n, 28670 Villaviciosa de Odón, Madrid, \\ Spain \\ vctxente@yahoo.es
}

\author{
Montaña Diaz-Manzano \\ Research Center in Applied Combat (CESCA). \\ Toledo, Spain \\ diazmanzano@hotmail.com
}

\begin{abstract}
Central fatigue related in sport stimuli was studied by Critical Flicker Fusion Threshold (CFFT) to know the influence of exercise on the central nervous system (CNS), but there is a lack of knowledge about the central or peripheral fatigue in endurance events. This study aimed to analyze changes in CFFT before and after the incremental cycle ergometer test as a means to assess the fatigue of the CNS. CFFT ascending and descending, the subjective criterion and sensory sensitivity were analyzed in 8 professional male cyclists $(72.1 \pm 5.59 \mathrm{~kg}, 180.3 \pm 6.43 \mathrm{~cm}, 17.4 \pm 0.7$ years $)$ before and after a maximum incremental cycle ergometer test (start $50 \mathrm{w}$ increases $50 \mathrm{w}$ each 5 minutes). In this incremental test, the induced fatigue was probably more a peripheral phenomenon than one due to central nervous system fatigue, because sensory sensitivity did not significantly decrease. In conclusion, an incremental cycle ergometer test increased the cortical arousal and does not affect negatively the CNS of professional cyclists.
\end{abstract}

\section{CCS CONCEPTS}

- Applied computing $\rightarrow$ Health care information systems • Computer systems organization $\rightarrow$ Special purpose systems • Hardware $\rightarrow$ Emerging tools and methodologies $\bullet$ Hardware $\rightarrow$ Biology-related information processing

\section{KEYWORDS}

Cortical Arousal, Central Nervous System, Fatigue, Flicker Fusion Threshold, Sport.

Permission to make digital or hard copies of all or part of this work for personal or classroom use is granted without fee provided that copies are not made or distributed for profit or commercial advantage and that copies bear this notice and the full citation on the first page. Copyrights for components of this work owned by others than the author(s) must be honored. Abstracting with credit is permitted. To copy otherwise, or republish, to post on servers or to redistribute to lists, requires prior specific permission and/or a fee. Request permissions from Permissions@acm.org.

TEEM'18, October 24-26, 2018, Salamanca, Spain

(C) 2018 Copyright is held by the owner/author(s). Publication rights licensed to ACM.

ACM ISBN 978-1-4503-6518-5/18/10...\$15.00

http://dx.doi.org/10.1145/3284179.3284258
ACM Reference format:

V. J. Clemente-Suárez and M. Diaz-Manzano. 2018. Evaluation of cortical arousal by critical flicker fusion threshold in cyclists. In Proceedings of the 6th International Conference on Technological Ecosystems for Enhancing Multiculturality (TEEM 2018) (Salamanca, Spain, October 24-26, 2018), F. $\mathcal{F}$. García-Peñalvo Ed. ACM, New York, NY, USA, 4 pages. https://doi.org/10.1145/3284179.3284258

\section{INTRODUCTION}

One of the causes of decreased performance in athletes is fatigue of central nervous system (CNS) [1]. The influence of physical effort in fatigue of CNS is an area little studied. One of the methods frequently used to measure fatigue of CNS and cognitive function is critical flicker fusion threshold (CFFT). The utility of CFFT in sport has been focused in the relationship of arousal level with CNS [2]. Increase in CFFT suggests an increase in cortical arousal and sensory sensitivity. By contrast, a decrease of CFFT suggests a reduction in the efficiency of the system to process information [3]. Another author also relationship CFFT whit fatigue of CNS, so that if the values fall below the baseline means that there is fatigue of CNS [4,5].

CFFT was affected by non-sensory and sensory factors. The results must be interpreted considering two different parameters. The parameter relationship whit sensory factor was subjective criterion (CS), which reflects the response criterion. This response can be conservative or liberal. The parameter relationship whit non-sensory factor was sensory sensitivity (SS). In methods will explain the form to calculate this parameter [6].

Several authors studied the CFFT in different sport stimuli. There was analyzed incremental VO2max test [6], 30 minutes maximum trial [7], 70\% of VO2max cycling trial [8], incremental cycling test [9]; 120' cycling trial [10], 270km ultraendurance run relay event [11]; exercise to exhaustion [12] or RSA speed test [13]. Only in exhaustion exercise and speed test presented a decreased in CFFT, showing a fatigue of CNS. In other stimuli only appear increased the cortical arousal.

These results show that efforts performed at maximal speed and with greater involvement of force appear to further affect the 
CNS. These exercises due to its high intensity could strain the CNS [14] and cause a decrease in performance of the athletes. The present research aims to study modifications in CFFT as measured of cortical arousal and fatigue of CNS in an incremental cycloergometer test in professional cyclists.

\section{METHODS}

\subsection{Participants}

We analyzed 8 volunteer male professional trained cyclists. They compete at international level in professional cycling teams. Participants were informed of the characteristics of the study and the test that took place and the potential risks derived from those who are exposed, also, they all signed a consent form in accordance with the declaration of Helsinki. The anthropometrical characteristic of participants is showed in Table 1.

Table 1. Anthropometrical characteristic of participants

\begin{tabular}{ll}
\hline & Average \pm SD \\
\hline Age (years) & $17.4 \pm 0.7$ \\
Weight $(\mathrm{kg})$ & $72.1 \pm 5.59$ \\
Height $(\mathrm{cm})$ & $180.3 \pm 6.43$ \\
BMI $\left(\mathrm{kg} / \mathrm{m}^{2}\right)$ & $22.2 \pm 1.65$ \\
Percentage of fat $(\%)$ & $14.1 \pm 2.69$ \\
Muscle mass $(\mathrm{kg})$ & $22.2 \pm 1.65$ \\
VO2max absolute $(\mathrm{l})$ & $5.95 \pm 0.53$ \\
VO2max relative $(\mathrm{ml} / \mathrm{Kg} / \mathrm{min})$ & $83.24 \pm 4.06$ \\
\hline
\end{tabular}

BMI - Body mass index; VO2max - maximal oxygen uptake.

\subsection{Procedure}

Body composition was analyzed with Inbody 230 (Biospace, Seoul, Korea). Incremental cycling test was developed in a cicloergometer (Lode Excalibur, Lode BV, Groningen, Holland), previously adapted to each cyclist. Incremental test started at intensity of $50 \mathrm{w}$ for 10 minutes, after increase the intensity $50 \mathrm{w}$ each 5 min until exhaustion. All incremental test was performed between 90-105 rpm. In the last minute of each series we analyzed lactate concentration, heat rate and Rating of Perceived Exertion (RPE). With lactate values we calculated the anaerobic threshold with previous methodologies [15-19], associating power, heart rate and RPE in this physiological moment. We also analyzed the maximal heart rate and RPE at maximal power at the end of the test.

Heart rate was measured through Polar S810. (Polar Electro Ibérica. Barcelona). RPE was measured with 6-20 RPE scale [9]. Blood lactate concentration was analyzed with Dr. Lange Miniphotometer plus LP 20. v 1.4.

The CFFT measurements were carried out before and immediately after the Wingate test. Participants were seated in front of a viewing chamber (Lafayette Instrument Flicker Fusion Control Unit Model 12021), which was constructed to control extraneous factors that might distort CFFT values. Two lightemitting diodes $(58 \mathrm{~cd} / \mathrm{m} 2)$ were presented simultaneously in the viewing chamber, one for the left eye and one for the right eye. The stimuli were separated by $2.75 \mathrm{~cm}$ (center to center) with a stimulus-to-eye distance of $15 \mathrm{~cm}$ and a viewing angle of $1.9^{\circ}$. The inside of the viewing chamber is painted flat black to minimize reflection. The flicker frequency increment $(1 \mathrm{~Hz} / \mathrm{sec})$ changed in two ways: either it increased from 0 to $100 \mathrm{~Hz}$ until the participant perceived fusion, or it decreased from 100 to $0 \mathrm{~Hz}$ until flicker was detected. After a fovea binocular fixation, participants were required to respond by pressing a button upon identifying the visual flicker (descending frequency) and the fusion (ascending frequency) thresholds. Prior to the experiment they performed as many practice trials as needed to become familiarization with the exigencies of the CFF test. Then, three ascending and three descending trials were performed alternatively $[6,20,21]$. Subjects carried out the test three times with an interval of 5 seconds (Figure 1).

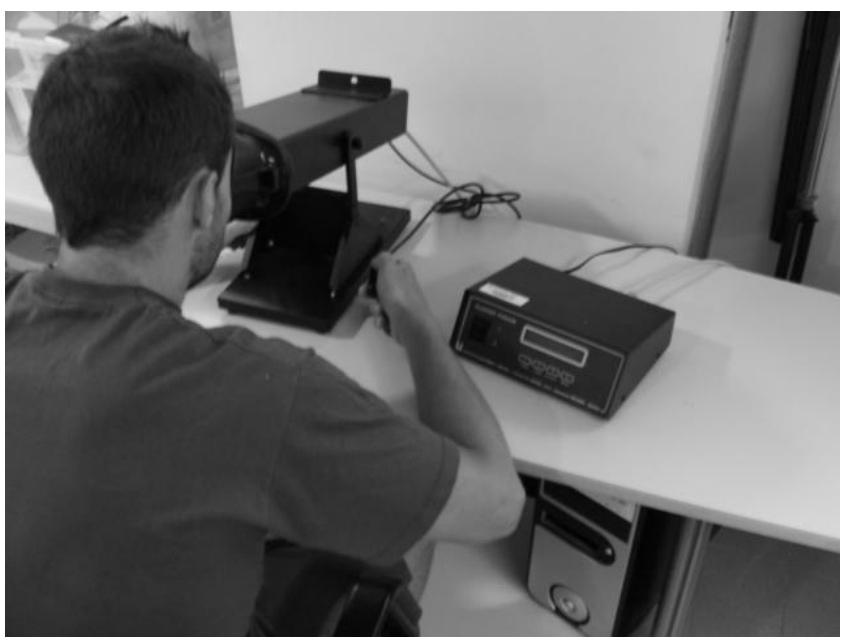

Figure 1. Participant conducting the CFF test

In each one of the test, time was quantified as the amount of time that a subject took for detecting the changes in the lights from the beginning of the test until the moment to pressing a button, to be able to determine the CFFT:

- CFFa - (Critical Flicker Fusion ascending), value obtained in the ascending test.

- CFFd - (Critical Flicker Fusion descending), value obtained in the descending test.

- $\quad$ SC (Subjective Criterion), difference among the stocking of the values obtained in the ascending test and the stocking of the values obtained in the descending test

- SS - (Sensorial Sensibility), median of the sum of the values obtained in the ascending test and descending test. 


\subsection{Statistical Analysis}

The data collected in this study were analyzed with the SPSS 17.0 statistical program. First, the normality of the sample was checked with the Shapiro-Wilks test and then a Friedman test was performed. The level of significance was set at $\mathrm{p}<0.05$ for all the comparisons.

\section{RESULTS}

Results showed how CFFa increased significantly after conducting the incremental cycling test $(\mathrm{p}<0.05)$, with a small effect size. However, CFFd as well as SS parameters increased not significant as we can see in Table 2, with a moderate effect size both. CS values presented a not significant increase with a small effect size.

Table 2. Flicker Fusion Threshold obtained in the cycling test

\begin{tabular}{llllll}
\hline & Pre & Post & $\begin{array}{l}\% \\
\text { Change }\end{array}$ & $\begin{array}{l}\text { Cohen's } \\
\text { D }\end{array}$ & $\mathrm{p}$ \\
\hline $\begin{array}{l}\text { CFFa } \\
(\mathrm{Hz})\end{array}$ & $35.1 \pm 10.7$ & $39.1 \pm 3.6$ & 11.3 & 0.37 & .042 \\
$\begin{array}{l}\mathrm{CFFd} \\
(\mathrm{Hz})\end{array}$ & $40.2 \pm 6.0$ & $41.2 \pm 1.7$ & 2.5 & 0.17 & .092 \\
$\begin{array}{l}\mathrm{SC} \\
(\mathrm{Hz})\end{array}$ & $-5.1 \pm 11.7$ & $-2.1 \pm 4.3$ & 41.2 & 0.26 & .091 \\
$\begin{array}{l}\mathrm{SS} \\
(\mathrm{Hz})\end{array}$ & $37.7 \pm 6.5$ & $40.2 \pm 18$ & 6.6 & 0.38 & .168 \\
\hline
\end{tabular}

CFFa Critical Flicker Fusion ascending; CFFd - Critical Flicker Fusion descending; SC - Subjective Criterion; SS - Sensorial Sensibility.

Description of physiological variables of the test measured are shown in table 3. Cyclists reached a maximum rated of perceived exertion at a maximal power of $350 \mathrm{w}$.

Table 3. Incremental test physiological data.

\begin{tabular}{lc}
\hline & Average \pm SD \\
\hline Maximal Power (W) & $350.0 \pm 26.73$ \\
\hline Maximal Heart Rate (bpm) & $184.6 \pm 10.98$ \\
\hline Maximal RPE & $19.5 \pm 0.76$ \\
\hline Power in Anaerobic Threshold (W) & $148.3 \pm 22.01$ \\
\hline $\begin{array}{l}\text { Heart Rate in Anaerobic Threshold } \\
\text { (bpm) }\end{array}$ & $145.7 \pm 14.19$ \\
\hline RPE in Anaerobic Threshold & $12.3 \pm 2.31$ \\
\hline RPE - Rated of perceived exertion
\end{tabular}

\section{DISCUSSION}

The present research aims to study modifications in CFFT as measured of cortical arousal and fatigue of CNS in an incremental cycloergometer test in professional cyclists. The results showed how after the incremental cycloergometer test SS values increased not significantly $6.6 \%$. This increase showed how this type of stimuli increases the cortical arousal [3]. These data are different than the obtained in a repeated sprints test RSA [13]. Despite being two high-intensity stimuli that develops in a high intensity, incremental test does not seem to adversely affect the CNS. This may be due to the temporal duration of incremental test is higher than each of the sprints repetitions of the RSA test. In the RSA test subjects develop anaerobic alactic power and anaerobic alactic capacity, while in incremental test develop first aerobic and anaerobic threshold and after developing aerobic power, in the end of the test. Possibly, because of these differences in metabolic rules used in each effort, obtain different results in SS values in an incremental and RSA tests. These results suggest that alactic stimuli have a greater effect in CNS and stimuli in which the aerobic metabolism is highly activated only cause an increase in cortical arousal without fatigue of CNS. Also, the data obtain are different than the obtained in triathletes tested after an exercise to exhaustion, since they showed symptoms of CNS fatigue [12]. In this line, also ultraendurance mountain event produce a decrease of SS [22]. We can see that endurance efforts to exhaustion and maximal speed stimuli seem to cause fatigue of CNS. Incremental test developed since aerobic condition, in firth stage, until exhaustion, with increment in the workload output. May be because minor duration of incremental test than exhaustion test of Godefroy et al, subjects of present research do not present fatigue of CNS.

The results found in this study were similar than the SS increase after a VO2max test in adult subjects [6]; in a 30 minutes maximum trial [7]; in an incremental cycling test [23]; 1RM squat test [24]; an incremental maximum cycling test [25]; in a RSA performed by professional football players [13]; and in a $70 \%$ of VO2max cycling trial [8]. We can see how high intensity effort with duration between $30 \mathrm{~s}$ to $30 \mathrm{~min}$ do not affect negative CNS. Only sprints stimuli can affect negative CNS. This result showed he influence of different physiological stimuli in cortical arousal, this information joining the knowledge about the effect of different psychological stimuli, like the negative effect of stress perception and the increased sympathetic nervous system associated in cortical arousal and information processing [26-38], allow us a better compression of psychophysiology of CNS. In addition, the increase in CS values suggests that the subjective criterion is conservative, and change observed after incremental test was linked to a cautious strategy [39].

\subsection{Practical applications}

The use of CFFT in sport area could be an effective training tool to avoid overtraining state, since it could report direct information about cortical arousal, information vital for a correct periodization of training, especially in new periodization training models as reverse periodization, where high intensity training has to be distributed in training cycles with caution due to the large psychophysiological requirements of these training [15,17,18,40$42]$. In addition, no only endurance sport as cycling could be beneficed by the CFFT use, resistance-based sport as weightlifting, 
or combat sports could also improve the distribution of training loads with this system.

\subsection{Limitation of the study}

The main limitation of the present study can be addressed regarding the small sample size evaluated. Due to the difficulty of recruit professional cyclist it was not possible to recruit larger participants for this study. The analysis of high performance athletes is difficult since it is difficult to stop carrying out your daily workouts to perform evaluation tests. Even so, the present investigation managed to analyze a whole cycling team.

Another possible limitation could be the use of CFFT to analyze cortical arousal. This method, although validated and extensively used in previous research is less accurate when compared to electroencephalogram or positron emission tomography. The accessibility, lower cost and the possibility of the use in specific sport events, make CFFT it more practical and easily usable by sport professionals.

\section{CONCLUSION}

In an incremental test, the induced fatigue was probably more a peripheral phenomenon than one due to central nervous system fatigue, because SS did not significantly decrease. In conclusion, an incremental cycle ergometer test increased the cortical arousal and does not affect negatively the CNS of professional cyclists.

\section{REFERENCES}

[1] Tomporowski PD. Effects of acute bouts of exercise on cognition. Acta Psychol 2003;112(3):297-324.

[2] Görtelmeyer R, Wiemann H. Retest reliability and construct validity of critical flicker fusion frequency. Pharmacopsychiatry 1982;15(S 1):24-28.

[3] Li Z, Jiao K, Chen M, Wang C. Reducing the effects of driving fatigue with magnitopuncture stimulation. Accident Anal Prev 2004;36(4):501-505

[4] Costa G. Evaluation of workload in air traffic controllers. Ergonomics 1993;36(9):1111-1120.

[5] Saito S. Does fatigue exist in a quantitative measurement of eye movements? Ergonomics 1992;35(5-6):607-615.

[6] Davranche K, Pichon A. Critical flicker frequency threshold increment after an exhausting exercise. J Sport Exer Psychol 2005;27(4):515.

[7] Clemente V. Fatiga del sistema nervioso después de una prueba de contrarreloj de $30^{\prime}$ en cicloergómetro en ciclistas jóvenes. Motricidad.Eur J Hum Mov 2010;25.

[8] Presland JD, Dowson MN, Cairns SP. Changes of motor drive, cortical arousal and perceived exertion following prolonged cycling to exhaustion. Eur J Appl Physiol 2005;95(1):42-51.

[9] Clemente-Suárez VJ. Fatigue of nervous system through Flicker Fusion thresholds after a maximum incremental cycling test. J Sport Health Res 2011;3(1):1-21.

[10] Grego F, Vallier J, Collardeau M, Rousseu C, Cremieux J, Brisswalter J. Influence of exercise duration and hydration status on cognitive function during prolonged cycling exercise. Int J Sports Med 2005;26(01):27-33.

[11] Clemente Suárez VJ, Martínez Trigo R. Fatiga del sistema nervioso mediante umbrales Flicker Fusion después de una prueba de ultrarresistencia por relevos de $200 \mathrm{~km}$. CCD 2010;5(13). DOI: http://dx.doi.org/10.12800/ccd.v5i13.64

[12] Godefroy D, Rousseu C, Vercruyssen F, Cremieux J, Brisswalter J. Influence of physical exercise on perceptual response in aerobically trained subjects. Percept Mot Skills 2002;94(1):68-70.

[13] Clemente-Suárez VJ, Muñoz V, Melus M. Fatiga del sistema nervioso después de realizar un test de capacidad de sprints repetidos (RSA) en jugadores de fútbol profesionales. Arch Med Deporte 2011;28(143):174-180.

[14] Herrera G, Callejón D, Urena A, Santos J, Hernández L, Callejón D. Voleibol. Madrid: Voleibol; 1992.

[15] Clemente-Suárez V. J., Fernandes RJ, de Jesus K, Pelarigo J, Arroyo-Toledo J.J., Vilas-Boas JP. Do traditional and reverse swimming training periodizations lead to similar aerobic performance improvements? J Sports Med Phys Fitness 2018;58(6):761-767

[16] Clemente-Suárez VJ, Delgado-Moreno R, González B, Ortega J, Ramos-Campo DJ. Amateur endurance triathletes' performance is improved independently of volume or intensity based training. Physiol Behav 2018. doi 10.1016/j.physbeh.2018.04.014

[17] Clemente-Suarez VJ, Dalamitros AA, Nikolaidis PT. The effect of a short-term training period on physiological parameters and running performance: intensity distribution versus constant-intensity exercise. J Sports Med Phys Fitness 2018 Jan-Feb;58(1-2):1-7.

[18] Clemente-Suárez VJ, Dalamitros A, Ribeiro J, Sousa A, Fernandes RJ, Vilas-Boas JP. The effects of two different swimming training periodization on physiological parameters at various exercise intensities. Eur J Sport Sci 2017;17(4):425-432.

[19] Clemente-Suarez VJ. Periodized training archive better autonomic modulation and aerobic performance than non periodized training. J Sports Med Phys Fitness 2017 Jun 21.

[20] Clemente-Suárez VJ. The Application of Cortical Arousal Assessment to Control Neuromuscular Fatigue During Strength Training. J Mot Behav 2017;49(4):429434.

[21] Clemente-Suárez VJ, Robles-Pérez JJ. Psycho-physiological response of soldiers in urban combat. An Psychol 2013;29(2):598-603.

[22] Belinchon-deMiguel P, Clemente-Suárez VJ. Psychophysiological, Body Composition, Biomechanical and Autonomic Modulation Analysis Procedures in an Ultraendurance Mountain Race. J Med Syst 2018;42(2):32.

[23] Clemente V. Fatigue of nervous system through Flicker Fusion thresholds after a maximum incremental cycling test. J Sport Health Res 2011;3(1):1-21.

[24] Clemente-Suárez VJ, Huertas C, Juárez D. Nervous system fatigue flicker fusion thresholds after performing a test of maximal strength in squat. Rev Entrenamiento Deportivo 2011;25(3):5-9.

[25] Clemente-Suarez VJ, Martínez A, Muñoz V, González J. Fatigue of central nervous system after an incremental maximal oxygen uptake test. Arch Med Deporte 2010; 137:107-118.

[26) Delgado-Moreno R, Robles-Pérez JJ, Clemente-Suárez VJ. Combat Stress Decreases Memory of Warfighters in Action. J Med Syst 2017;41(8]:124

[27] Delgado-Moreno R, Robles-Pérez J. J., Aznar S, Clemente-Suarez VJ. Inalambric Biofeedback Devices to Analyze Strength Manifestation in Military Population. J Med Syst 2018;42(4):60. DOI: 10.1007/s10916-018-0914-9.

[28] Diaz-Manzano M, Robles-Pérez JJ, Herrera-Mendoza K, Herrera-Tapias B, Fernández-Lucas J, Aznar-Lain S, et al. Effectiveness of Psycho-Physiological Portable Devices to Analyse Effect of Ergogenic Aids in Military Population. J Med Syst 2018;42(5):84

[29] Tornero-Aguilera J, Robles-Pérez JJ, Clemente-Suárez VJ. Use of Psychophysiological Portable Devices to Analyse Stress Response in Different Experienced Soldiers. J Med Syst 2018;42(4):75.

[30] Tornero-Aguilera JF, Clemente-Suarez VJ. Effect of experience, equipment and fire actions in psychophysiological response and memory of soldiers in actual underground operations. Int J Psychophysiol 2018;128:40-46.

[31] Tornero-Aguilera JF, Robles-Pérez JJ, Clemente-Suárez VJ. Effect of Combat Stress in the Psychophysiological Response of Elite and Non-Elite Soldiers. J Med Syst 2017;41(6):100.

[32] Sánchez-Molina J, Robles-Pérez JJ, Clemente-Suárez VJ. Assessment of psychophysiological response and specific fine motor skills in combat units. J Med Syst 2018;42(4):67.

[33] Sánchez-Molina J, Robles-Pérez JJ, Clemente-Suárez VJ. Effect of parachute jump in the psychophysiological response of soldiers in urban combat. J Med Sys 2017;41(6):99.

[34] Bellido A, Ruisoto P, Beltran-Velasco A, Clemente-Suárez VJ. State of the Art on the Use of Portable Digital Devices to Assess Stress in Humans. J Med Syst 2018;42(6):100.

[35] Beltrán-Velasco AI, Bellido-Esteban A, Ruisoto-Palomera P, Clemente-Suárez VJ. Use of Portable Digital Devices to Analyze Autonomic Stress Response in Psychology Objective Structured Clinical Examination. J Med Syst 2018;42(2):35.

[36] Clemente-Suarez VJ, Palomera PR, Robles-Pérez JJ. Psychophysiological response to acute-high-stress combat situations in professional soldiers. Stress Health 2018;34(2):247-252.

[37] Clemente-Suárez VJ, Robles-Pérez JJ, Fernández-Lucas J. Psychophysiological response in parachute jumps, the effect of experience and type of jump. Physiol Behav 2017;1(179):178-183.

[38] Clemente-Suarez VJ, Robles-Pérez JJ, Herrera-Mendoza K, Herrera-Tapias B, Fernández-Lucas J. Psychophysiological response and fine motor skills in highaltitude parachute jumps. High Alt Med Biol 2017;18(4):392-399.

[39] Ghozlan A, Widlöcher D. Ascending-descending threshold difference and internal subjective judgment in CFF measurements of depressed patients before and after clinical improvement. Percept Mot Skills 1993;77(2):435-439.

[40] Clemente-Suárez VJ, Arroyo-Toledo JJ. The Use of Autonomic Modulation Device to Control Training Performance after High-Intensity Interval Training Program. J Med Syst 2018;42(3):47.

[41] Arroyo-Toledo JJ, Clemente Suárez VJ, González Ravé JM. Effects of Traditional and Reverse Periodization on Strength, Body-Composition and Swim Performance. Imp J Interdiscip Res 2016;2(12):474-481.

[42] Arroyo-Toledo JJ, Clemente VJ, Gonzalez-Rave JM, Ramos Campo DJ, Sortwell A. Comparison between traditional and reverse periodization: swimming performance and specific strength values. Int J Swimming Kinetics 2013;2(1):87-96 